\title{
Studying the Impact of Golgi Protein 73 Serving as a Candidate Biomarker in Early Diagnosis for Hepatocellular Carcinoma among Saudi Patients
}

\author{
Randa Mohamed Ahmed Farag ${ }^{1 *}$, Dujana Al Ayobi ${ }^{2}$, Khalid AAlsaleh ${ }^{3}$, Hye-Joo \\ Kwon $^{4}$, Afaf EL-Ansary ${ }^{5}$, Emad Anwar Dawoud ${ }^{6}$
}

\begin{abstract}
Background: Due to the prevalence of Hepatocellular carcinoma (HCC) in Saudi Arabia, using new markers to give best diagnostic performance than alpha-feto protein (AFP) are important in early diagnosis. The aim of this work was to compare the significance between serum and mRNA Golgi glypican73 (GP-73) as newly identified diagnostic and prognostic markers for HCC among Saudi patients. Materials and Methods: A total of 300 subjects were divided into: 250 blood samples where 145 samples from HCC, 105 samples from chronic liver cirrhosis (CLC) and 50 normal controls were investigated for serum GP73 (sGP73) by ELISA. GP-73 mRNA from peripheral blood mononuclear cells was amplified by RT-PCR. The sensitivity and specificity of both techniques was compared. Results: Serum Golgi glypican 73 was significantly higher in HCC group compared to cirrhotic and normal controls $(\mathrm{p}<0.001)$. Sensitivity and specificity were $95 \%$ for sGP-73, $100 \%$ and $90 \%$ for Golgi glypican 73 mRNA. The combination of sensitivity between AFP and sGP73 was $80 \%$ and $95 \%$ respectively. Conclusion: Both serum Golgi glypican-73 and GP-73Mrna are good diagnostic biomarkers for early detection of HCC in Saudi patients. RT-PCR is more accurate and sensitive $(100 \%)$ than ELISA (95\%) in detecting Golgi glypican 73.
\end{abstract}

Keywords: Golgi glypican73- Sandwich ELISA- RT-PCR- early surveillance- HCC- Saudi Arabia

Asian Pac J Cancer Prev, 20 (1), 215-220

\section{Introduction}

According to Saudi Cancer Registry, 2010, Hepatocellular Carcinoma (HCC) was detected in $4.8 \%$ of all newly detected cases of all types of cancer in Saudi patients. It ranked fourth in males and eighth in females with a male to female ratio of $2.1: 1$ and it accounts for $83 \%$ and $80 \%$ of all liver cancers in males and females, respectively (Saudi Cancer Registry, 2010).

In fact, the majority of $\mathrm{HCC}$ are associated with a background of chronic liver diseases. Therefore, development of HCC is hypothesized to involve multiple genetic changes over a long period of time. Infection with hepatitis $\mathrm{B}$ virus (HBV) and hepatitis $\mathrm{C}$ virus (HCV) contributes significantly to the causal agent of HCC. The great majority (nearly $80 \%$ ) of HCC cases worldwide is associated with chronic infections with these two viruses (APA Liver consensus recommendations on HCC 2014). But in Saudi Arabia, Hepatitis C is also common with a prevalence rate of $1 \%$ to $3 \%$ of the population which further increases the risk of HCC (Madani, 2007; KSA Ministry of Health Statistics 2009).

The highly costs of a diagnostic program of liver malignant is considered the main problem in continuous follow-up. About $30 \%$ of liver cancer cases are without elevation in serum alpha-fetoprotein (AFP) levels. However, in other cases AFP levels were characterized with sensitivity and specificity when tumor size is more than 3 to $5 \mathrm{~cm}$ in hepatocellular carcinoma (HCC) (Abdo et al., 2012; Flores and Marrero 2014). Therefore, the identification of new biomarkers with high sensitivity and specificity than AFP could be helpful in early diagnosis of Hepatocellular carcinoma (HCC) (Gish 2014; Shaker et al., 2017).

Golgi glypican 73 (GP73) also named Golgi phosphoprotein 2, which was introduced as diagnostic and prognostic marker to identify HCC (Kladney et al., 2000). GP73 is a resident Golgi-specific membrane expressed by biliary epithelial cells and is enhanced in HCC cells (Mao et al., 2010). It has been found and is expressed in

${ }^{1}$ Health Sciences Research Center (HSCR), ${ }^{2}$ Department of Biology, ${ }^{4}$ Department of Molecular Biology, Princess Nourah bint Abdulrahman University (PNU), ${ }^{3}$ Department of Medicine, Oncology Centre, King Khalid University Hospital, King Saud University, ${ }^{5}$ Central Labe, King Saud University Riyadh, Kingdom Saudi Arabia, ${ }^{6}$ Faculty of Medicine, EL-Azher University and Specialist Physician, Oncology Clinic-Medical Affaies, Tawam Hospital, AL Ain, UAE.*For Correspondence: randa792006@ gmail.com 
HBV, HCV infection, alcoholic liver disease, also at high concentration in HCC patients (Anand et al., 2015).

This study advocates evaluating and comparing the sensitivity and specificity of serum and mRNA Golgi glypican 73 in diagnostic HCC patients from cirrhotic patients and normal controls and compared them with AFP. Also, it compares the sensitivity of ELISA and RT-PCR.

\section{Materials and Methods}

\section{Exclusion and Inclusion criteria for all patients}

Samples were collected from patients with a medical record and continuous follow-up to (ultra sound (US), MRI or CT) the level of liver cirrhosis and liver cancer and exclusion of cases that were met or did not have a medical record. Tumor staging was determined using the United Network of Organ Sharing-modified tumor-nodemetastasis staging system for HCC.

All studied subjects were collected from Pathology Department at King Faisal Specialist Hospital and Research Center (KFSHRC, Riyadh and Jeddah), Pathology Laboratory at Saudi German Hospitals (Riyadh, Jeddah, and Medina), Ministry of National Guard Hospitals, Princess Nourah Oncology Center, Jeddah, Security Forces Hospital Riyadh, Armed Forces Hospitals (Riyadh, Western, South and Northern), Public and Privet Hospitals in different regions in Saudi Arabia from July 2014 to May 2017.

Subjects with HCC on biopsy, a new hepatic defect, showed vascular enhancement on one imaging modality (US, MRI, or CT) with AFP $>1,000 \mathrm{ng} / \mathrm{mL}$. For the cirrhosis group, patients with hepatitis $\mathrm{C}$ and hepatitis $\mathrm{B}$ and biopsy-proven cirrhosis were enrolled. All controls healthy group were screened for hepatitis viruses before enrollment.

In the current study, tests were conducted on 300 blood samples, 250 blood samples of Hepatocellular carcinoma (HCC), chronic liver cirrhosis (CLC) and 50 blood samples of healthy control normal group. A total blood samples were $250 ; 185(74 \%)$ males and $65(26 \%)$ females with an age range from 23 to 78 years. The control group included 50 healthy subjects (blood donors 16 males and 4 females) with an age range between 22 and 60 years. Demographic and clinical information were obtained and a $20-\mathrm{ml}$ blood sample was collected from each subject in a serum separator tube and spun within 2 $\mathrm{h}$, and Centrifuged serum was stored at $-20^{\circ} \mathrm{C}$ for GP-73 protein and AFP assay.

The study was conducted after approval from the ethics committee of Institute Review Board (IRB), King Khalid University Hospital, King Saud university, College of Medicine, (14/4180/IRB). All written approvals were taken from patients before starting the study.

\section{Detection of tumor markers}

Serum Golig glypican -73 (GP73) was investigated by using a commercially available ELISA kit provided by LifeSpan (LifeSpan BioSciences, USA). A monoclonal antibody specific for GP73 is pre-coted onto a microplate. Five standard sample wells and one blank control well were assigned to each sample. The sample dilution of
$100 \mu \mathrm{l}$ and test specimen of $15 \mu \mathrm{l}$ were pipetted into each well, supplemented with standard samples of $0 \mathrm{ng}, 20 \mathrm{ng}$, $50 \mathrm{ng}, 120 \mathrm{ng}$ and $250 \mathrm{ng}(15 \mu \mathrm{leach})$. The microplates were sealed with sealing tapes and incubated at $37^{\circ} \mathrm{C}$ for $60 \mathrm{~min}$. The plates were sealed with sealing tapes again and incubated at $37^{\circ} \mathrm{C}$ for $30 \mathrm{~min}$. The plates were thoroughly rinsed for five times again and each well was supplemented with color reagents A and B (50 $\mu$ leach) for the color reaction at $37^{\circ} \mathrm{C}$ for $20 \mathrm{~min}$. Termination solution of $50 \mu \mathrm{l}$ was added into each well and the wavelength of enzyme labeling instrument was set at $450 \mathrm{~nm}$. The sample GP73 concentration was retrieved from the curve. The normal range of serum GP73 was $0-55 \mathrm{ng} / \mathrm{mL}$ and the malignancy was indicated in the case of GP73 $>100$ $\mathrm{ng} / \mathrm{mL}$ (Shi et al. 2011).

AFP was detected by using the Cobas 601 electrochemiluminescence immunoassay analyzer. It indicated positive in the case of serum AFP $>7 \mu \mathrm{g} / \mathrm{L}$.

Detection of Golgi glypican- 73 (GP73) mRNA by RT-PCR

Two $\mathrm{ml}$ of whole blood were placed in anticoagulant blood test tube (EDTA) for RNA extraction from peripheral mononuclear blood cells (PMBs). RNA extraction from PMBs was completed within $6 \mathrm{~h}$ after blood drawn. Extracted RNA was supplemented with ethanol of $2.5 \times$ volume and stored at $-80^{\circ} \mathrm{C}$ for the assay of GP73 mRNA (InviTrap Spin Blood RNA Mini Kit). The concentration of total RNA was determined with UV spectrophotometry and $500 \mathrm{ng}$ of total RNA was sampled for the reverse transcription polymerase chain reaction (RT-PCR). For the reverse transcriptase synthesis of cDNA, the reverse transcription reaction system $(20 \mu \mathrm{l})$ consisted of 5-3 PrimeScript ${ }^{\mathrm{TM}}$ buffer $(4 \mu \mathrm{l})$, Prime- Script ${ }^{\mathrm{TM}}$ RT Enzyme Mix I ( $1 \mu \mathrm{l})$, Oligo dT Primer $(50 \mu \mathrm{M}, 1 \mu \mathrm{l})$ and Random 6 mers $(100 \mu \mathrm{M}, 1 \mu \mathrm{l})$. RNase-free distilled water $(\mathrm{dH} 2 \mathrm{O})$ was supplemented to reach the total system volume at 20 $\mu 1$. The reverse transcription was performed at $37^{\circ} \mathrm{C}$ for $20 \mathrm{~min}$ and $85^{\circ} \mathrm{C}$ for $5 \mathrm{sec}$.

The GP73 and internal control $\beta$-actin quantitative PCR system consisted of SYBR Premix Ex Taq ${ }^{\mathrm{TM}}$ (10.0 $\mu \mathrm{l})$, PCR forward primer $(10 \mu \mathrm{M}, 1.6 \mu \mathrm{l})$, PCR reverse primer $(10 \mu \mathrm{M}, 1.6 \mu \mathrm{l})$, DNA template $(2.0 \mu \mathrm{l})$ and sterile distilled water ( $4.8 \mu \mathrm{l})$, respectively. The RT-PCR was performed as following. Denaturation at $95^{\circ} \mathrm{C}$ for $10 \mathrm{sec}$, then 40 cycles of $95^{\circ} \mathrm{C}$ for $5 \mathrm{sec}, 64^{\circ} \mathrm{C}$ for 30 sec and $72^{\circ} \mathrm{C}$ for $10 \mathrm{sec}$. The upstream primer sequence of GP73 was 5'-CAGCGCTGATTTTGAGATG-3' and its downstream primer sequence was 5'-ATGATCCGTGTCTGGAGGTC-3', with the target gene size at $156 \mathrm{bp}$. The upstream primer sequence of $\beta$-actin was 5'-CGTACCACTGGCATCGTGAT-3' and its downstream primer sequence was 5'-GTGTTGGCGTACAGGTCTTTG-3', with the target gene size at $452 \mathrm{bp}$.

\section{Statistical analysis}

Data was analyzed using IBM SPSS advanced statistics version 20 (SPSS Inc., Chicago, IL). Qualitative data were expressed as frequencies and percentages. For quantitative data, a comparison between two groups was done using Mann-Whitney test (non-parametric t-test). A comparison between three groups was done using Kruskal-Wallis test 
(non-parametric ANOVA) then post-Hoc "Schefe test" on rank of variables was used for pair-wise comparison. Numerical data were expressed as medians and ranges. Spearman-rho method was used to test the correlation between numerical variables. The Receiver Operating Characteristic (ROC) curve was used for prediction of cut off values. The $\mathrm{p}$-value $<0.05$ was considered significant. Sensitivity, specificity, positive predictive value (PPV) and negative predictive values (NPV) were calculated for the different markers used.

\section{Results}

The demographic features of the included population were as follows: the total population in this study was 300 samples (250 blood samples of (Hepatocellular carcinoma (HCC) and chronic liver cirrhosis (CLC)) and 50 blood samples of normal control). A total blood (serum) samples were $250 ; 185(74 \%)$ males and 65 (26\%) females with an age range from 23 to 78 years. The control group included 50 healthy subjects (blood donors 16 males and 4 females) with an age range between 22 and 60 years.

Two hundred fifty blood samples included $145 \mathrm{HCC}$ (male (95\%) 138/145; female (5\%) 7/145) with hepatitis viruses were 105 (72\%) patients with $\mathrm{HCV}$-positive; 20 (17\%) were HBV infection and $20 \mathrm{HCC}$ patients were negative for both viral hepatitis markers. Also, 105 CLC (CLD led to LC without HCC) were 67\% males (70/105), $33 \%$ females (30/105). Also, 75 (71\%) with hepatitis viruses $(37 / 75$ (49\%) with HCV-positive, $27 / 75$ (36\%) with HBV-positive, 11/75 (15\%) cases co-infected with

Table 1 .The Demographic Feature of the Hepatocellular Carcinoma (HCC) and Chronic Liver Cirrhosis (CLC)

\begin{tabular}{lcc}
\hline Characteristics & $\begin{array}{c}\text { Patients with } \\
\text { HCC } \\
(\mathrm{n} 145)\end{array}$ & $\begin{array}{c}\text { Patients without } \\
\text { HCC (CLC) } \\
(\mathrm{n}=105)\end{array}$ \\
\hline Gender (\%) & $\begin{array}{c}138 / 145(95 \%) \\
\text { M } 70 / 105(67 \%)\end{array}$ & $\begin{array}{c}\text { F } 30 / 105(33 \%) \\
\text { Male/Female }\end{array}$ \\
Hepatitis virus (\%) & $20 / 125(16 \%)$ & $27 / 75(36 \%)$ \\
HBV & $105 / 125(84 \%)$ & $37 / 75(49 \%)$ \\
HCV & N/A & $11 / 75(15 \%)$ \\
HBV+HCV & $125 / 145(86 \%)$ & $75 / 105(71 \%)$ \\
Chronic Hepatitis/LC (\%) & $20 / 145(14 \%)$ & $30 / 105(29 \%)$ \\
Chronic non Hepatitis /L C (\%) & & \\
Tumor size & $105 / 145$ & N/A \\
$\leq 2 \mathrm{~cm}$ & $40 / 145$ & N/A \\
$>2 \mathrm{~cm}$ and $\leq 3 \mathrm{~cm}$ & &
\end{tabular}

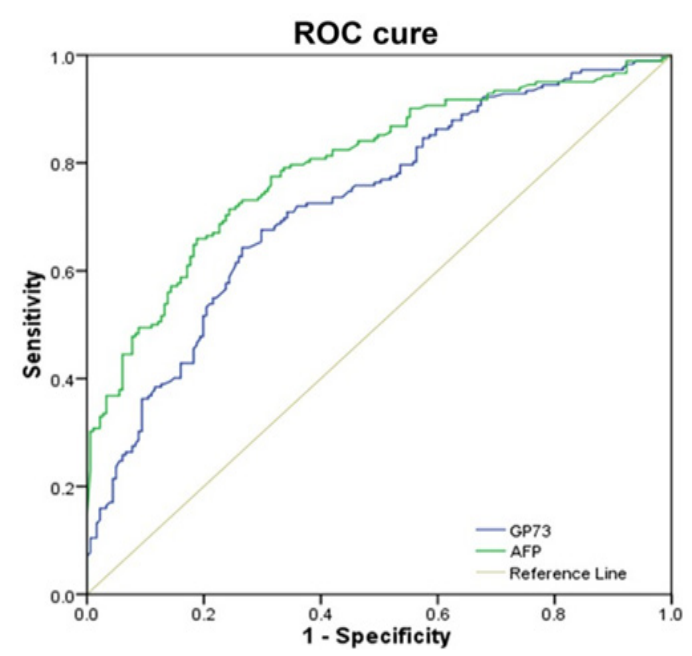

Figure 1. The Roc Curve for Golgi Glypican-73 and AFP

both hepatitis viruses] and 30/105 (29\%) patient were negative for both HCV, HBV hepatitis viruses included 10/30 (33\%) (Table 1).

Serum Golgi glypican-73 (GP-73) and Alph-feto protein (AFP) show significantly different results in Hepatocellular carcinoma (HCC) compared to cirrhotic (CLC) and healthy normal control group $(\mathrm{p}<0.001)$.

Detection of sGolgi glypican -73 by ELISA showed a high positivity rate in HCC 95\% (138/145) patients. Compared to CLC, it was $12.4 \%(13 / 105)$ and it was negative in the normal group $(\mathrm{p}<0.001)$. Golgi glypican -73 mRNA detected by RT-PCR was positive in $100 \%$ of cases in HCC group (Figure 2) and it was 26.6\% (28/105) positivity in CLC group and was not detected in healthy control group $(\mathrm{p}<0.001)$. On the other hand, AFP

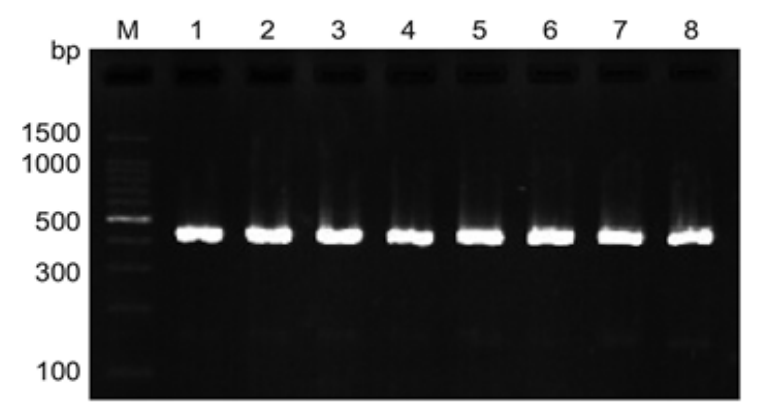

Figure 2. RT-PCR of Golgi Glypican-73 (GP73) Gene Expression in Peripheral Blood Samples. (Lane M, show $100 \mathrm{bp}$ of molecular Wight marker, Lane 1,4 Whole blood from HCC, Lane 5, 6 whole blood CLC and Lane 7, 8 control group).

Table 2. Diagnostic Performance of sGP-73, GP-73mRNA Compared with Alpha-Fetoprotein

\begin{tabular}{lccc}
\hline & $\begin{array}{c}\text { s Golgi glypican-73 } \\
\text { (cutoff 4.9 ng/ml) }\end{array}$ & $\begin{array}{c}\text { sAFP } \\
\text { (cutoff 40.5 ng/ml) }\end{array}$ & Golgi glypican-73mRNA \\
\hline Sensitivity\% (95\% CI)* & $95(85.5-98.7)$ & $80(70.1-90.7)$ & $100(91.0-100.0)$ \\
Specificity\% (95\% CI) & $95(85.2-98.7)$ & $80(70.9-90.5)$ & $90(68.0-98.0)$ \\
Positive Predictive value \% (95\% CI) & $97.5(88.5-99.7)$ & $91(80.9-94.9)$ & $95(83.0-99.0)$ \\
Negative Predictive value \% (95\% CI) & $90.5(79.4-96.2)$ & $70.8(57.5-81.5)$ & $100(81.0-100.0)$ \\
Diagnostic Accuracy \% (95\% CI) & 95 & 80.3 & 96 \\
\hline
\end{tabular}


measurement revealed $80 \%$ positivity in $\mathrm{HCC}$ group, $25 \%$ positivity in the cirrhosis group, and was negative in the normal control group $(\mathrm{p}<0.001)$.

Median levels of sGolgi glypican -73 were 125,62 , $0.89 \mathrm{ng} / \mathrm{ml}$ and AFP were $147.5,15,3.2 \mathrm{ng} / \mathrm{ml}$ in the HCC group, cirrhosis group, and normal control group, respectively.

One hundred five out of 145 of the HCC patients (72.4\%) were HCV positive and 40/145 (27.6\%) were HBV positive. All hepatitis positive HCC patients were cirrhotic.

In HCC patients, the highest results of sGolgi glypican-73 were detected in HBV and HCV positive compared to $\mathrm{HBV}$ and $\mathrm{HCV}$ negative patients. It was $96 \%$ (120/125), 70\% (14/20) in positive and negative hepatitis virus HCC patients respectively. As for AFP, the highest results were detected in $\mathrm{HBV}$ and $\mathrm{HCV}$ positive patients (Table 2). In CLC patients, sGolgi glypican-73 by ELISA were detected in $14.7 \%(11 / 75$ in positive $\mathrm{HBV}$ and $\mathrm{HCV})$ and $6.6 \%(2 / 30$ in negative $\mathrm{HBV}, \mathrm{HCV})$ and compared to Golgi glypican -73mRNA detected by RT-PCR was positive in 33\% (23/75), 16.6\% (5/30) in +ve/-ve HBV, HCV respectively.

As shown in Figure 1, the area under curve of GP73 was $0.896 \pm 0.027$ and its $95 \%$ confidence interval was 0.833 to 0.939 . GP73 could be used for the diagnosis of early surveillance of HCC. The area under curve of AFP was $0.818 \pm 0.034$ and its $95 \%$ confidence interval was 0.741 to 0.875 . Thus, the diagnostic value of GP73 was higher than that of AFP.

As shown in Figure 2, the band of $\beta$-actin was 452 bp and that of $156 \mathrm{bp}$ was the target gene of GP73. The expression of the GP73 gene remained constant in normal control while the band density of the target gene GP73 was higher in HCC specimens than in CLC specimens, so expression of GP73 mRNA was significantly up-regulated in HCC specimens than in normal control group.

As for the diagnostic performance of two biomarkers, the sensitivity, specificity, positive predictive value, negative predictive value and diagnostic accuracy for sGolgi glypican-73 were $(95 \%, 95 \%, 97.5 \%, 90.5$ and $95 \%$ ) respectively at cut off $4.9 \mathrm{ng} / \mathrm{ml}$ and for AFP were $(80 \%, 80 \%, 91 \%, 70.8$ and $80.3 \%)$ respectively at cut off $40.5 \mathrm{ng} / \mathrm{ml}$. For Golgi glypican 73 mRNA, they were (100 $\%, 90 \%, 95 \%, 100 \%$ and $96 \%$ ) respectively (Table 2 ).

\section{Discussion}

In fact, the surveillance programs of $\mathrm{HCC}$ has evolved significantly over the past few decades (Page et al., 2014). Unfortunately, the most of it depends on alpha fetoprotein (AFP), even in combination with abdominal ultrasound (Mustafa et al., 2013). However, some reports recorded that the sensitivity for the detection of HCC ranges between $25 \%-60 \%$, and its specificity is low and AFP can also be detected in patients with cirrhosis (11\%-47\%) and chronic hepatitis without cirrhosis (15\%-58\%) (Abdulaziz and AL-Salloom, 2016). In addition, 30\% HCC patients present with normal AFP. Thus, they needed for new tumor markers that can differentiate between HCC and benign hepatic lesions and this is very important for early surveillance and specific diagnosis of HCC (Salim et al., 2009; Shaker et al., 2017).

This study was focused on Golgi protein-73 (GP73) as a new biomarker, which is a $73-\mathrm{kD}$ resident Golgi membrane protein of unknown function. GP73 is a type II trans membrane protein with a single, $\mathrm{N}$-terminal trans membrane domain and an extensive, C-terminal coiled-coil domain located on the luminal surface of the Golgi apparatus (Marrero and Romano 2005; Comunale et al., 2006).

It was recently reported that GP73 was detected in biliary epithelial cells in patients with acute hepatitis, cirrhosis and HCC (Marrero and Romano 2005). GP73 values are higher in early HCC patients than in cirrhotic patients; GP73 is considered a possible biomarker for screening the diagnosis of early HCC (Comunale et al., 2006).

In the HCC group, GP-73 mRNA was the most sensitive among the studied markers for diagnosing HCC among Saudi patients with $100 \%$ positivity rate, followed by sGP73 $(95 \%)$, then AFP $(80 \%)$. Also, in cirrhosis group, GP-73 mRNA showed the highest positivity (49.6\%), followed by AFP which was (25\%) then sGP-73 $(20.7 \%)$. The three markers were negative in the normal control group.

A comparison of sGP-73 and AFP between the three studied groups showed a significant difference between HCC and both liver cirrhosis and normal groups. This is in accordance with other researchers (Marrero and Romano 2005; Comunale et al., 2006; Shan et al., 2013; Zhang et al., 2015).Serum levels of GP-73 and AFP levels increased in the HCC patients and were negative in other benign liver cases (Yamaoto et al., 2010). The absence of serum GP-73 in healthy individuals was also reported by some previous studies (Mao et al., 2010; Zhou et al., 2012).

As regards the diagnostic performance, Sensitivities of GP-73 mRNA, sGP73 and AFP were (100\%, 95\% and $80 \%)$. Specificities were $(90 \%, 95 \%$ and $80 \%)$ respectively. GP-73 mRNA is more sensitive but low specific than sGP73 and both are highly sensitive and specific for diagnosing $\mathrm{HCC}$ and differentiating $\mathrm{HCC}$ from benign liver conditions and normal controls than does AFP.

Our findings demonstrated that serum GP-73 in HCC group significantly differed from those in cirrhosis, hepatitis and normal control group, indicating that in Saudi patients, GP-73 was significantly elevated in HCC serum as a good biomarker for early surveillance of HCC. That was because of the release of GP-73 protein by hepatoma cells into the circulation in first stage HCC patients, resulting in the significantly elevated sGP73 in HCC. These results indicated that the hepatitis cirrhotic patients also had GP-73 elevated, that was consistent with the study's results of Kladney et al., (2002), Rieneret al., (2009), Hu et al., (2010) and Anand et al., (2015) indicating that GP-73 was highly up-regulated in both acute and chronic hepatic disorders in Saudi patients.

Several studies have shown that Golgi glypican 73 is superior to AFP in early detection of HCC, being highly sensitive and specific (Gu et al., 2009; Zhou et al., 2012; Shan et al., 2013). The comparison of ROC curves for 
Gp73 and AFP displayed that GP-73 was more accurate than AFP in the diagnosis of HCC. The sensitivity of sGP-73 was $95 \%$ and AFP was $80 \%$ in HCC consistent with the findings of Block et al., (2005), Gu et al., (2009) and $\mathrm{Hu}$ et al. (2010).

As regards GP-73 expression at mRNA level by RT-PCR, our results revealed that GP-73mRNA was detected in all cases of HCC $(100 \%)$, in cirrhosis patients was $(49.6 \%)$ and was not detected in any of the normal healthy controls. Our results were in agreement with Comunale et al., (2006); Riener et al., (2009); Mao et al., (2010); Shi et al., (2011); Shan et al., (2013) these studies reported similar results concluding that GP-73mRNA is significantly up-regulated in HCC compared to normal and benign liver samples, and hence GP-73 mRNA could serve as a molecular tumor biomarker for early detection of HCC.

Regarding the one hundred five cirrhotic patients, included in the present study, twenty eight of them were positive for GP-73mRNA. These cases were followed up for 12 months. The nineteen who were positive hepatitis viruses also have mildly elevated sGP-73 and AFP levels has been diagnosed as HCC after 6 months of follow up. These results could support that GP-73 can be used for screening and early detection of HCC among cirrhotic patients. This was in accordance with Comunale et al., (2006), who demonstrate that during the follow up of their patients with liver cirrhosis having detectable sGP-73 levels, HCC developed within 6 months among a considerable number of patients with a significant change of serum AFP levels.

The lack of correlation between Gp-73 and positivity of $\mathrm{HBV}$ and $\mathrm{HCV}$ infection in this study proves the high specificity of GP-73 in HCC versus non HCC hepatitis cases, as positivity of $\mathrm{HBV}$ or $\mathrm{HCV}$ infection will not give false positive results especially in Saudi patients, where there is a continuous prevalence of hepatitis viral infection. Kladney et al., (2000) reported that GP-73 was present in the serum of HCC patients, but was undetectable in all patients with hepatitis as well as healthy individuals. Maitra et al., (2004) proposed that GP-73 was highly expressed in both acute and chronic hepatic patients, indicating that such protein was less helpful for the etiological diagnosis of hepatic disorders but could be used as their serum biomarker. On the other hand, Morota et al., (2011) demonstrated that Gp-73 evaluated in the serum of patients with chronic hepatitis, cirrhosis, and hepatocellular carcinoma.

Comparing the sensitivity of two techniques used, GP-73by RT-PCR proved to be more sensitive (100\%) than ELISA (95\%).

Trans membrane protein of Golgi apparatus does not seem to play a critical role in tumor progression even not expressed by hepatocytes, the viral infection induced the overall, up regulation expression of GP-73 in hepatocytes HCC, this strongly suggests that GP-73 is a good molecular biomarker for early surveillance of HCC. Estimation of GP-73 diagnostics and immunotherapeutic target may help in prevention and treatment of liver cancer (Kladney et al., 2000; Mao et al., 2010; Shan et al., 2013; Anand et al., 2015).
In conclusion, GP-73 is a highly sensitive and specificity diagnostic biomarker for HCC which can be used in early detection of HCC and in screening and follow up of patients with cirrhosis among Saudi population. There is no impact for the presence of hepatitis viruses on the diagnostic accuracy of Golgi glypican 73 in diagnosing HCC among Saudi patients. Measuring GP-73mRNA by RT-PCR proved to be more sensitive (100\%) than GP-73 by ELISA (95\%), and it is more suitable for follow up of cirrhotic patients. Further studies with larger sample sizes and longer follow up of HCC and chronic liver cirrhosis (CLC) patients are needed to estimate and clarify the role of Golgi glypican73 in early diagnosis of HCC.

\section{Acknowledgments}

The authors would like to thank King Abdul Aziz City for Science and Technology (KACST) for supporting the present work as part of NTPC funded projects no. AT-34-208.

\section{References}

Abdo AA, Hassanain M, AlJumah AR, et al (2012). Saudi guidelines for the diagnosis and management of hepatocellular carcinoma: technical review and practice guidelines. Ann Saudi Med, 32, 174-99.

Abdulaziz A, ALSalloom M (2016). An update of biochemical markers of hepatocellular Carcinoma. Int J Health Sci (Qassim), 10, 121-36.

Anand M, Harmin H, Timothy B (2015). Glycosylation and liver cancer. Adv Cancer Res, 126, 257-79.

Asian Pacific Association for the Study of the Liver consensus recommendations on Hepatocellular carcinoma (2014), http://apasl.info/apasl/wp- content/uploads/2014/02/ Guidelines-for-HCC- Management-2010.pdf.

Block TM, Comunale MA, Lowman M, et al (2005). Use of targeted glycoproteomics to identify serum glycoproteins that Correlate with liver cancer in woodchucks and humans. Proc Natl Acad Sci US A, 102, 779-84.

Cancer Incidence Report in Saudi Arabia, Saudi Cancer Registry (2010). http://www.chs.gov.sa/Ar/mediacenter/ NewsLetter/2010\%20Report\%20(1).pdf.

Comunale MA, Lowman M, Long RE, et al (2006). Proteomic analysis of serum associated fucosylated glycoproteins in the development of primary hepatocellular carcinoma. J Proteome Res, 6, 308-15.

Flores A, Marrero JA (2014). Emerging trends in hepatocellular carcinoma: focus on diagnosis and therapeutics. Clin Med Insights Oncol, 8, 71-6.

Gish R (2014). Early detection of Hepatocellular Carcinoma through surveillance using Biomarkers. Gastroenterol Hepatol, 10, 121-3

Gu Y, Chen W, Zhao Y, Chen L, Peng T (2009). Quantitative analysis of elevated serum Golgi Protein-73 expression in patients with liver diseases. Ann Clin Biochem, 46, 38-43.

Hu JS, Wu DW, Liang S, Miao XY (2010). GP73, a resident Golgi glycoprotein, is sensibility and specificity for hepatocellular carcinoma of diagnosis in a hepatitis B-endemic Asian Population. Med Oncol, 27, 339-45.

Kingdom of Saudi Arabia Ministry of Health Statistics (2009).

Kladney RD, Bulla GA, Guo L, et al (2000). GP73, a novel Golgi-localized protein upregulated by viral infection. Gene, 249, 53-65.

Kladney RD, Cui X, Bulla GA, Brunt EM, Fimmel CJ (2002). 
Expression of GP73, a resident Golgi membrane protein, in viral and nonviral liver disease. Hepatology, 35, 1431- 40.

Madani TA (2007). Hepatitis C virus infections reported in Saudi Arabia over 11 years of Surveillance. Ann Saudi Med, 27, 191-4.

Maitra A, Thuluvath PJ (2004). GP73 and liver disease, a (Golgi) complex enigma. Am J Gastroenterol, 99, 1096-8.

Mao Y, Yang H, Xu H, et al (2010). Golgi protein 73(GOLPH2) is a Valuable serum marker for hepatocellular carcinoma. Gut, 59, 1687-93.

Marrero J, Romano P (2005). GP73, a resident Golgi glycoprotein, is a novel serum marker for Hepatocellular carcinoma. J Hepatol, 43, 1007-12.

Morota K, Nakagawa M, Sekiya R, et al (2011). Acomparative evaluation of Golgi protein-73, fucosylated hemopexin, alpha- Fetoprotein, and PIVKA- II in the serum of patients with chronic hepatitis, cirrhosis, and hepatocellular carcinoma. Clin Chem Lab Med, 49, 711-8.

Mustafa MG, Petersen JR, Ju H, et al (2013). Biomarker Discovery for early detection of hepatocellular carcinoma in hepatitis C-infected Patients. Mol Cell Proteomics, 12, 3640-52.

Page AJ, Cosgrove DC, Philosophe B, Pawlik TM (2014). Hepatocellular carcinoma: Diagnosis, management, and prognosis. Surg Oncol Clin N Am, 23, 289-311.

Riener MO, Stenner F, Liewen H, et al (2009). Golgi phosphoprotein 2 (GOLPH2) expression in liver tumors and its value as a serum marker in hepatocellula Carcinomas. Hepatology, 49, 1602-9.

Salim EI, Moore MA, Al-Lawati JA, et al (2009). Cancer epidemiology and control in the arabworld - past, present and future. Asian Pac J Cancer Prev, 10, 3-16.

Shaker MK, Abdel Fattah HI, Sabbour GS, et al (2017). Annexin A2 as a Biomarker for hepatocellular carcinoma in Egyptian patients. World J Hepatol, 9, 469-76.

Shan SG, Gao YT, Xu YJ, et al (2013). Gradually increased Golgi Protein 73 expression in the progression of benign liver diseases to Precancerous lesions and hepatocellular carcinoma correlates with prognosis of Patients. Hepatol Res, 43, 1199-210.

Shi Y, Chen J, Li L, et al (2011) A study of diagnostic value of golgi protein GP73 and its genetic assay in primary hepatic carcinoma. Technol Cancer Res Treat, 10, 287-94.

Yamaoto K, Imamura H, Matsuyama Y, et al (2010). AFP, AFP- L3, DCP and GP73 as markers for monitoring treatment response and recurrence and as surrogate markers of clinicopathological variables of HCC. Gastroenterol, $\mathbf{4 5}$, 1272- 82 .

Zhang Z, Zhang Y, Wang Y, et al (2015). Alpha-fetoprotein-L3 and Golgi protein 73 may Serve as candidate biomarkers for diagnosing alpha-fetoprotein-negative hepatocellular Carcinoma. Onco Targets, 9, 123-9.

Zhou Y, Yin X, Ying J, Zhang B (2012) Golgi protein 73 versus alpha-fetoprotein as a Biomarker for hepatocellular carcinoma: a diagnostic meta-analysis. BMC Cancer, 12, 1 .

This work is licensed under a Creative Commons AttributionNon Commercial 4.0 International License. 